\title{
EFFECT OF DEM RESOLUTION ON LS FACTOR COMPUTATION
}

\author{
Anto Ryan Raj ${ }^{1}{ }^{*}$, Justin George ${ }^{1}$, Raghavendra $S^{1}$, Suresh Kumar ${ }^{1}$, Shefali Agrawal ${ }^{1}$
}

Indian Institute of Remote Sensing, Dehradun, India - antoryanraj@gmail.com, justin, raghav, suresh_kumar, shefali_a)@iirs.gov.in

\author{
Commission V, SS: Natural Resources Management
}

KEY WORDS: LS factor, DEM resolution, slope exponent, multi-flow direction algorithm, watershed.

\begin{abstract}
:
LS factor plays a key role in soil erosion risk assessment using widely adopted empirical models such as RUSLE (Revised Universal Soil Loss Equation). The study was carried out to estimate the impact of varying DEM resolutions on LS factor values in a small hilly watershed near Dehradun, India. The impact of various computational algorithms as well as varying slope exponents on LS factor values were also estimated. DEMs of different resolutions such as ASTER(30m), CARTOSAT(10m and 30m), SRTM(30m) and UAV generated DEM $(18 \mathrm{~cm})$ were used for comparison. On comparison, LS factor generated using varying resolution DEMs including UAV generated DEM yielded similar results indicated by similar mean values, even though the maximum values in the study area varied slightly. Use of spatially distributed slope exponent values resulted in higher mean LS factor values from all the DEMs, except UAV generated one, when compared to the use of a constant, slope exponent value. All DEMs except UAV generated DEM, yielded lower LS factor values when multi-flow direction (MFD) algorithm was used for computation instead of single flow direction (SFD). The variations in results when using UAV DEM may be due to its ability to capture the micro topographical variations on the ground, which affects the various computational procedures. The LS factor results obtained using different computational procedures and algorithms needs to be validated using ground collected information of LS factor, for wider acceptability and use by soil erosion and geospatial modelling communities.
\end{abstract}

\section{INTRODUCTION:}

The soil loss occurred during erosion process is highly influenced by the combined topographical factor, namely the LS factor. LS factor which is a combination of slope length factor (L factor) and slope steepness factor ( $\mathrm{S}$ factor) is an important parameter used to measure soil loss using Revised Universal Soil Loss Equation (RUSLE) (Renard et al., 1997). Digital Elevation Models (DEMs) plays an important role in studies concerning soil erosion with Remote Sensing and GIS. DEM is used for precisely locating the terrain features. The computation of $\mathrm{L}$ factor is dependent on the DEM accuracy (Liu et al., 2011). DEMs are more suitable in the representation of the continuous variation of the topographic Earth surface (Thompson et al., 2001). Latest developments in the GIS domain has led to computation of L factor from the DEM watershed (Hickey et al., 1994; Winchell et al., 2008).

The slope length (L) factor is calculated as given by (Wischmeier \& Smith, 1978):

$\mathrm{L}=(\lambda / 22.13)^{\mathrm{m}}$

Where 22.13 is the RUSLE plot length (metres), $\lambda=$ slope length, $\mathrm{m}=$ variable slope exponent. The accepted values of $\mathrm{m}$ usually ranges from 0.2 to 0.5 in a steep terrain.

$$
\begin{gathered}
m=\beta /(1+\beta) \\
\beta=(\sin \theta / 0.0896) /\left[3.0(\sin \theta)^{0.8}+0.56\right]
\end{gathered}
$$

Where $\beta=$ ratio of rill to interrill erosion, and $\theta=$ slope angle.

The slope steepness (S) factor is calculated as given by (McCool et al., 1989):

$$
\begin{array}{ll}
S=10.8 \sin \theta+0.03 & \theta<9 \% \\
S=16.8 \sin \theta-0.5 & \theta \geq 9 \%
\end{array}
$$

The study was undertaken with the objective of studying the effect of DEM resolution on computing the LS factor. A number of DEMs such as ASTER (30m), SRTM (30m), CARTODEM $(10 \mathrm{~m}$ and $30 \mathrm{~m})$ and UAV generated DEM $(18 \mathrm{~cm})$ are used to compare the differences in computing the topographical LS factor. The LS factor is also compared by taking the value of constant slope exponent (m) as well as spatially distributed slope exponent calculated by equations (2) and (3). An attempt was also made to analyse two algorithms to determine the flow direction, namely the single flow algorithm and multiple flow algorithm; hence the LS factor is compared according to these two algorithms which are given by(McCool et al., 1989) and(Desmet\&Govers,1996)

\footnotetext{
* Corresponding author
} 


\section{MATERIALS AND METHODS:}

\subsection{Study Area:}

The study area is located at Langha in Dehradun district of the state of Uttarakhand, India. The study area's coordinates falls between $30^{\circ} 26^{\prime} 43 " \mathrm{~N}$ to $30^{\circ} 28^{\prime} 28^{\prime \prime} \mathrm{N}$ latitude and $77^{\circ} 51^{\prime} 33^{\prime \prime} \mathrm{E}$ to $78^{\circ} 55^{\prime} 30^{\prime \prime} \mathrm{E}$ longitude. It is located at the Vikasnagar block towards west from Dehradun by $32 \mathrm{~km}$. It lies at an elevation of 648 meters above mean sea level. The study area comprises of a watershed of Asan river system, a tributary of river Yamuna.

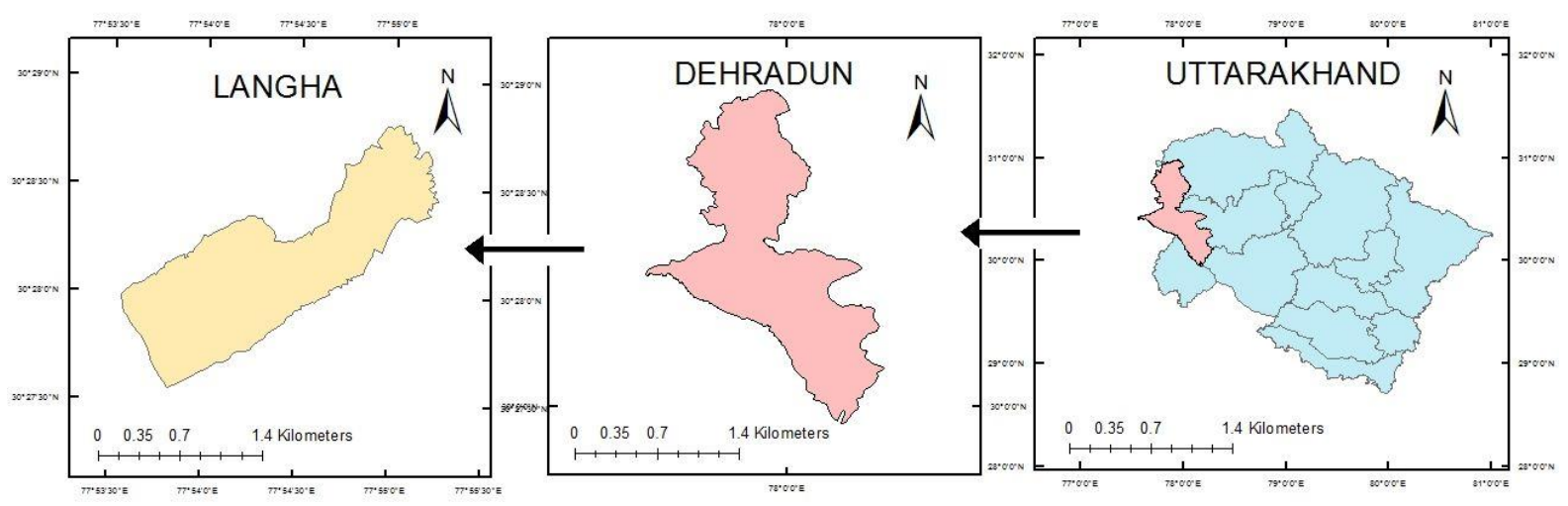

Figure 1: Study area

\subsection{DEM data acquisition:}

DEMs of various resolution including $10 \mathrm{~m}, 30 \mathrm{~m}$ and $18 \mathrm{~cm}$ were used in the study as given in Table 1. Coarser resolution $(10 \mathrm{~m}$ and $30 \mathrm{~m})$ DEMs were primarily obtained from the USGS and Bhuvan sources. For generating high resolution DEM, 232 photographs were acquired using DJI Inspire 2 drone. Further, they were processed in Agisoft software to generate DEM of $18 \mathrm{~cm}$ resolution. DEMs can have errors due to various sources of uncertainty such as positional and relative accuracy with errors in interpolation.

\begin{tabular}{|l|l|l|l|}
\hline DEM & Source & Elevation range & Version \\
\hline ASTER Global DEM (30m) & USGS & $719-1142$ & 2.0 \\
\hline $\begin{array}{l}\text { SRTM 1 Arc-Second } \\
\text { Global(30m) }\end{array}$ & USGS & $728-1138$ & 3.0 \\
\hline CARTODEM(10m) & Bhuvan & $671-1099$ & $2 \mathrm{R} 1$ \\
\hline CARTODEM(30m) & Bhuvan & $675-1099$ & $2 \mathrm{R} 1$ \\
\hline UAV generated DEM(18cm) & Optical processing & $753.34-1170.88$ & - \\
\hline
\end{tabular}

Table 1: DEMs used along with source, elevation and version

\subsection{Methodology:}

The overall methodology adopted in the study is shown in Figure 3.The software used in the DEM processing is ArcGIS. While most of the process are done in ArcGIS, ArcSAGA toolbox is also used to find the LS factor using (Desmet \& Govers, 1996) multiple flow algorithm. In ArcGIS using the hydrology toolset from spatial analyst toolbox, the fill operation is performed in order to fill the sinks (or depressions) to create a depressionless DEM. Then performing the flow direction operation, the flow path is obtained using the D-8 algorithm. The D-8 algorithm operates its flow in surrounding eight directions (left, right, up, down, and the four diagonal directions) from the cell. Using the input of flow direction raster, flow accumulation is calculated. The flow accumulation raster is used in computing the $\mathrm{L}$ factor. The $\mathrm{L}$ factor and $\mathrm{S}$ factor are calculated by using the raster calculator tool in ArcGIS with the corresponding equations for $\mathrm{L}$ and $\mathrm{S}$ factors. By multiplying $\mathrm{L}$ and $\mathrm{S}$ factor maps, the LS factor map in raster format is obtained. Comparison of the obtained LS factor map is done with respect to the variations in DEM resolution, slope exponent and flow algorithms. 

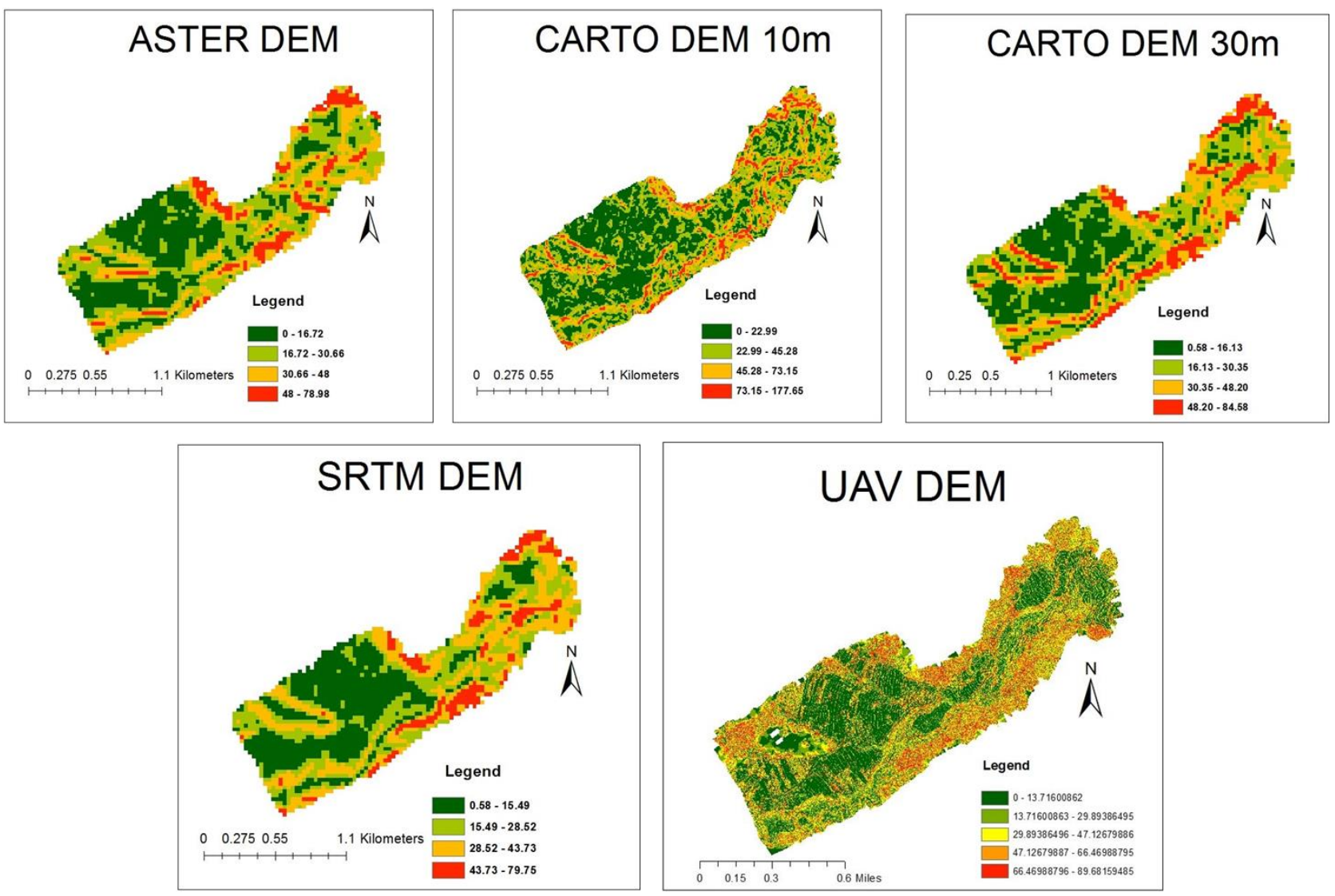

Figure 2: Slope maps dervied using different DEMs

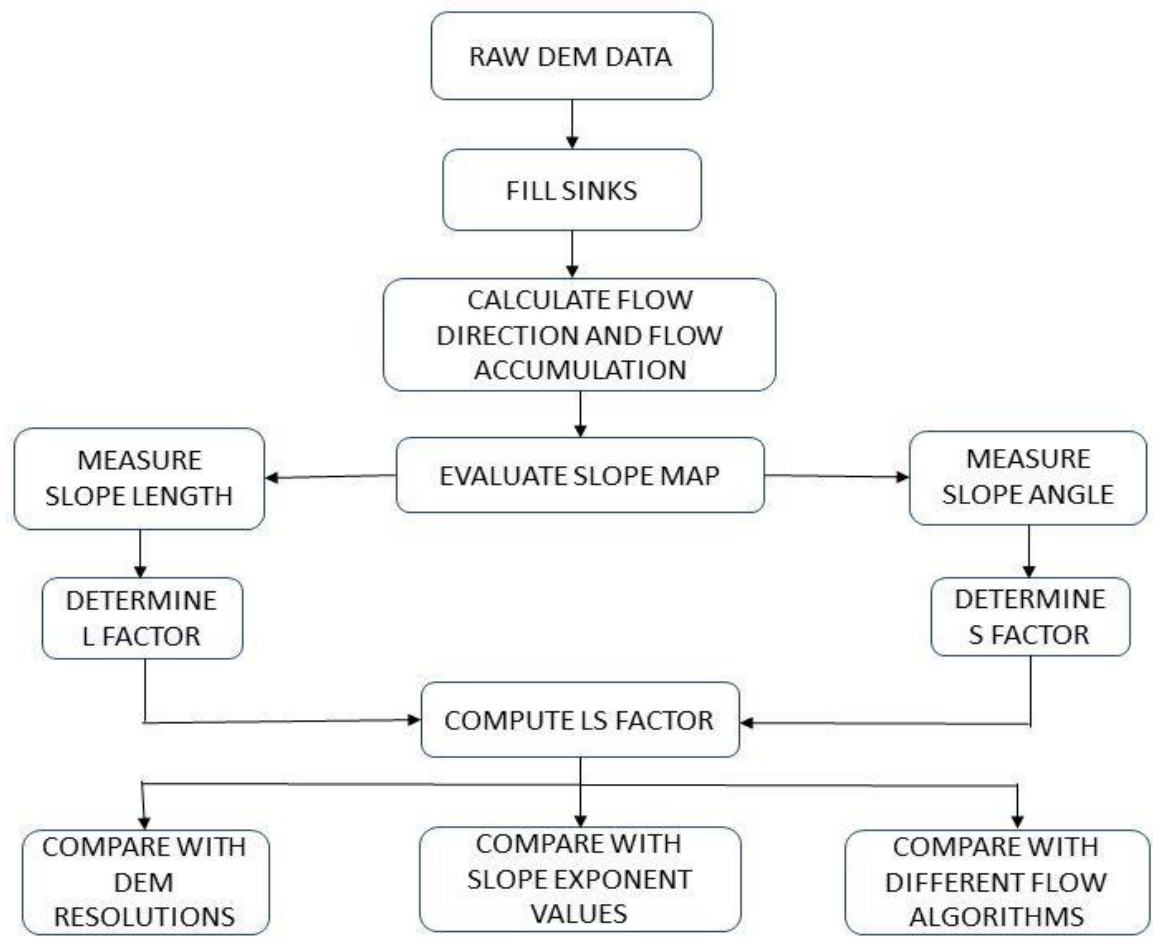

Figure 3: Methodology flowchart of the process involved 


\section{RESULTS AND DISCUSSIONS:}

Considering the L-factor and S-factor equations, for each DEM, LS-factor maps are computed. LS factor is computed on the basis of the criteria involving constant slope exponent $(\mathrm{m}=0.14)$, spatially distributed slope exponent by creating a raster with equations (2) and (3), and adopting an equation based on multiple flow algorithm unlike the previous criteria which uses the single flow algorithm. Single flow algorithm transfers matter from source cell to single cell whereas multiple flow algorithm transfers to several receiving cells. It is also noted that single flow algorithm has a parallel and convergent flow but multiple flow algorithm has a divergent flow. These three criteria helps to make a better comparison of the DEMs irrespective of their varying resolutions.

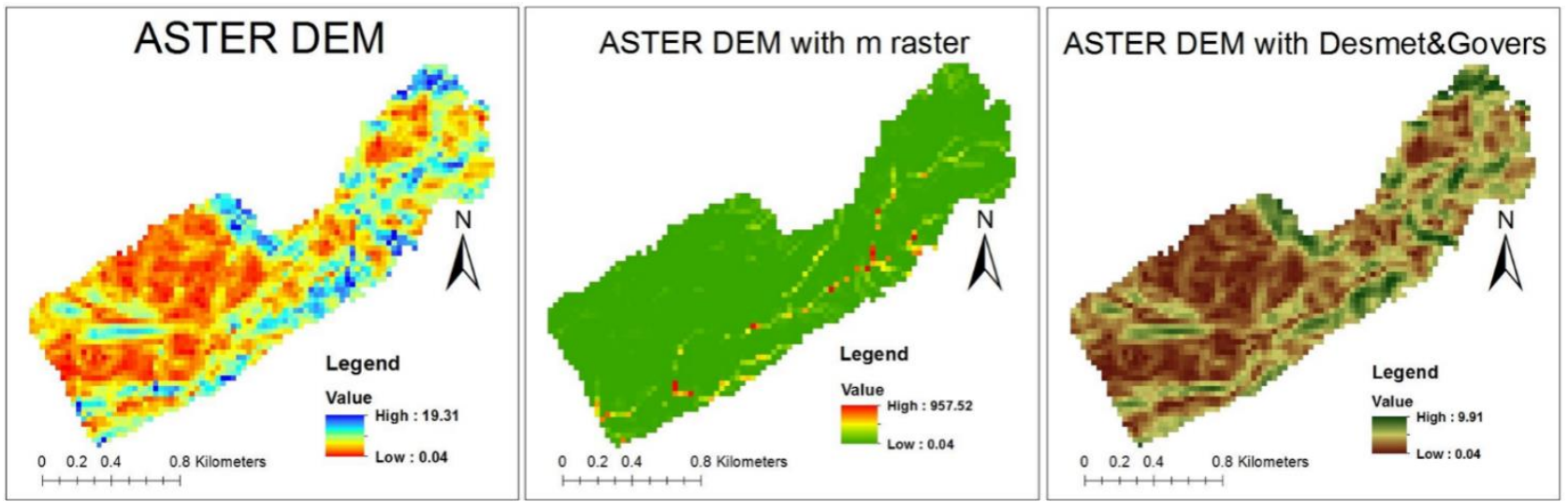

Figure 4: LS factor of ASTER DEM with constant slope exponent, spatially distributed slope exponent and with multiple flow algorithm
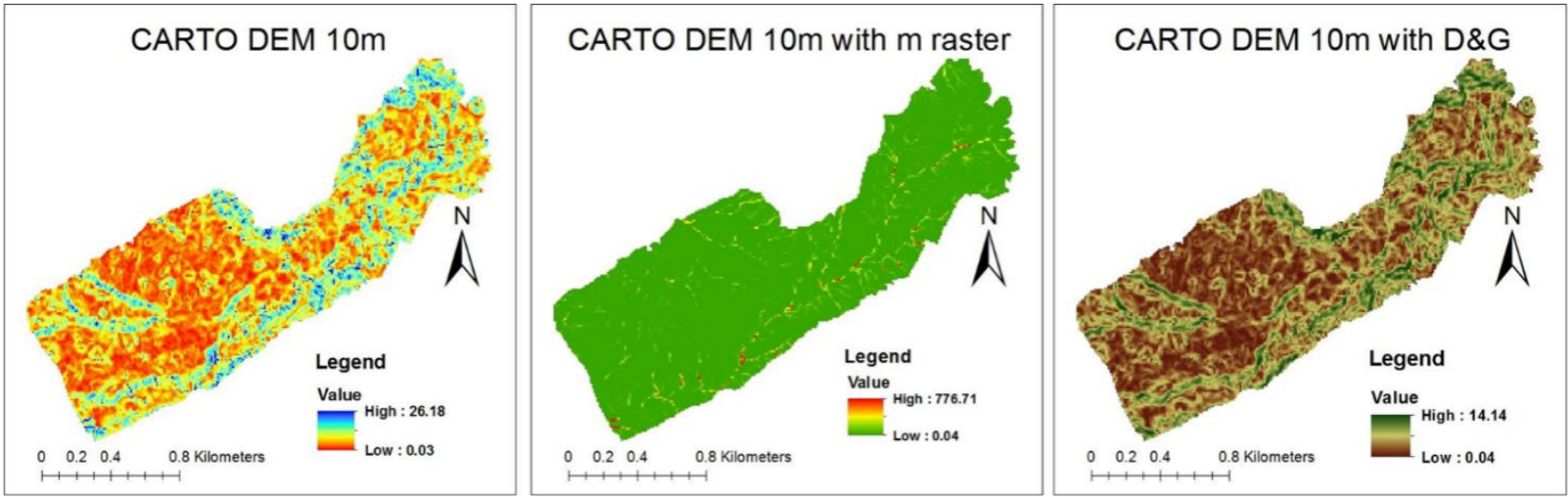

Figure 5: LS factor of CARTO DEM 10m with constant slope exponent, spatially distributed slope exponent and with multiple flow algorithm

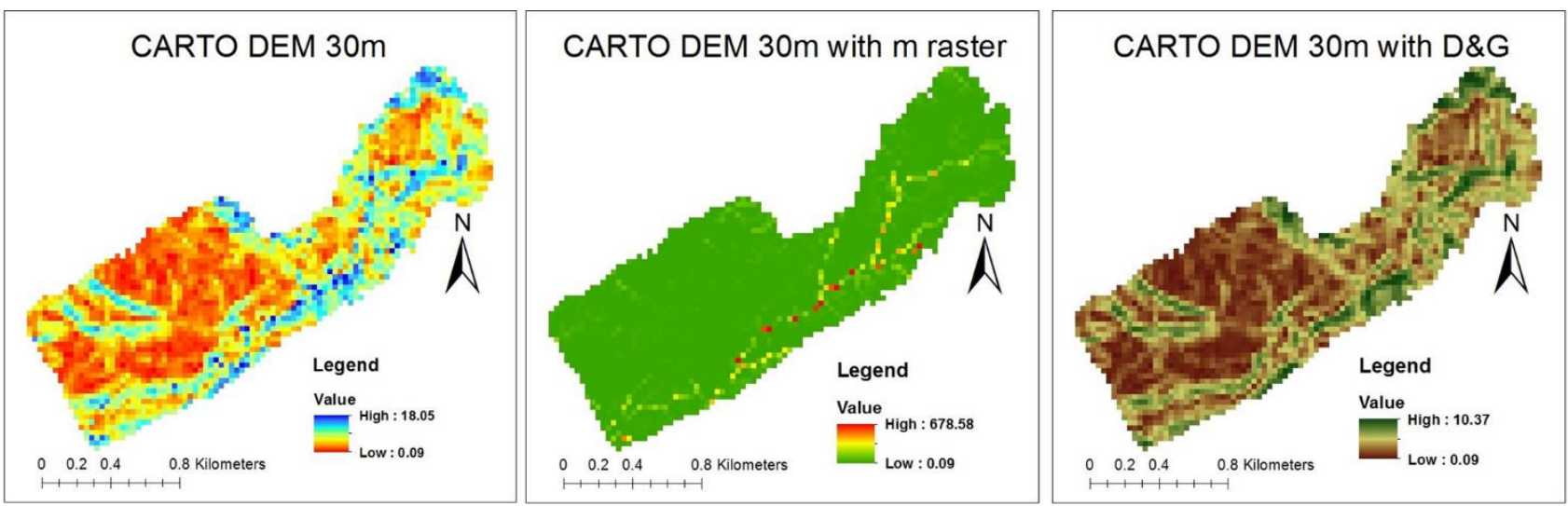

Figure 6: LS factor of CARTO DEM 30m with constant slope exponent, spatially distributed slope exponent and with multiple flow algorithm 

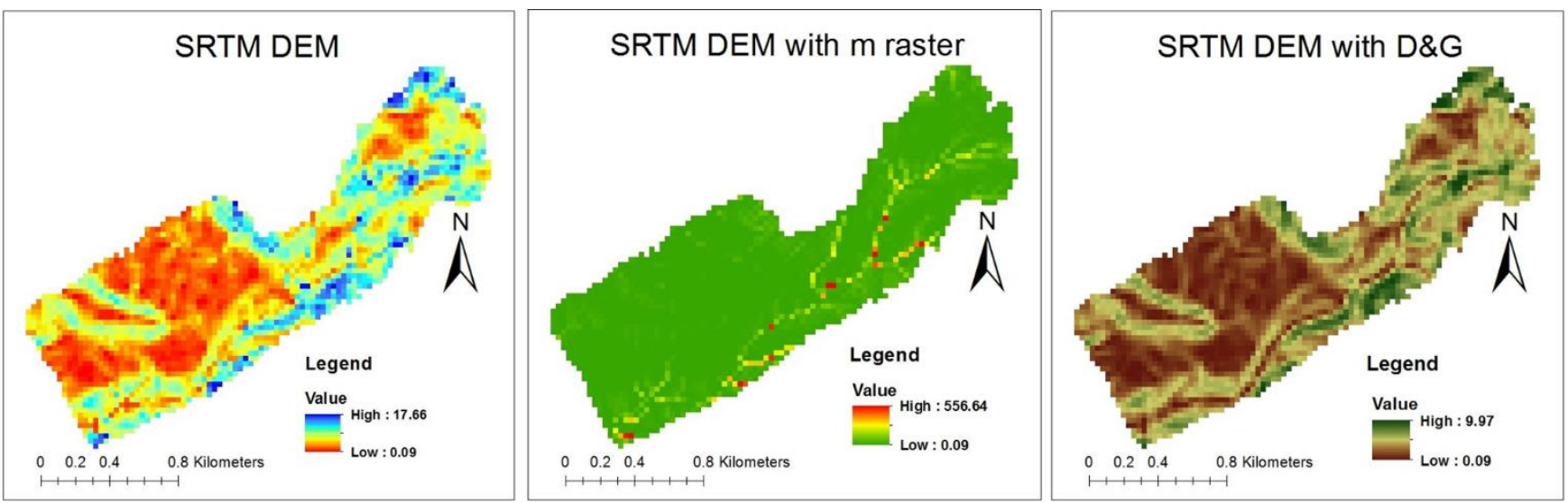

Figure 7: LS factor of SRTM DEM with constant slope exponent, spatially distributed slope exponent and with multiple flow algorithm
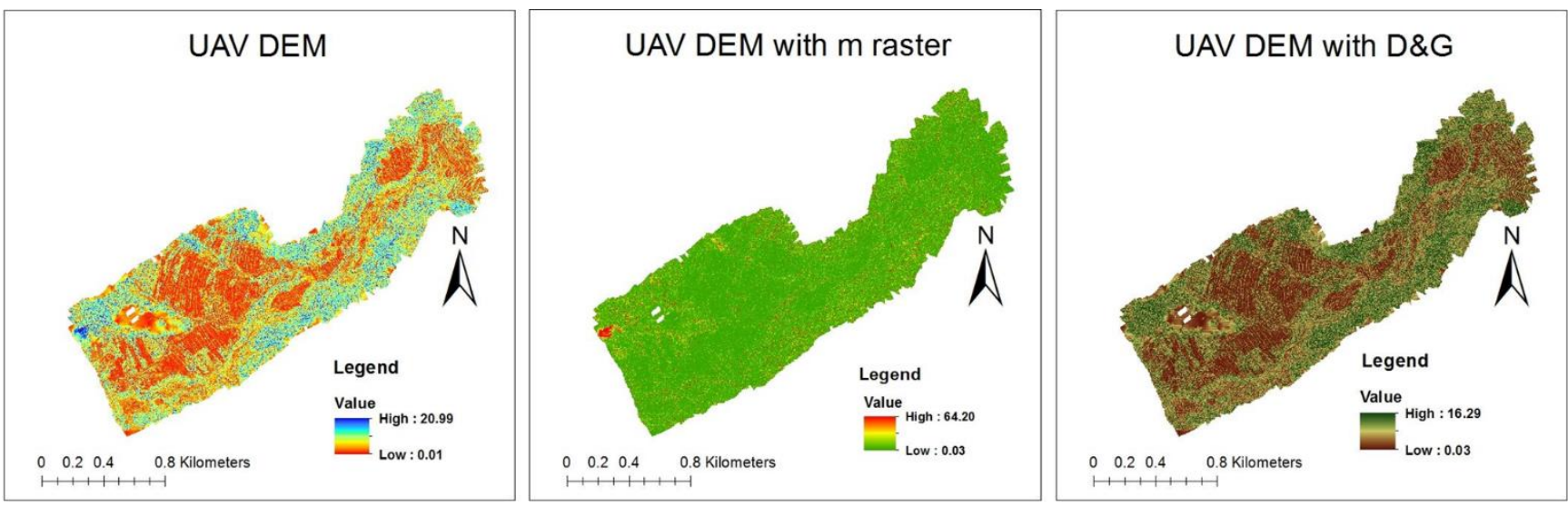

Figure 8: LS factor of UAV DEM with constant slope exponent, spatially distributed slope exponent and with multiple flow algorithm

\begin{tabular}{|l|l|l|l|l|l|}
\hline Parameter & ASTER 30m & CARTO 10m & CARTO 30m & SRTM 30m & UAV 18cm \\
\hline Min & 0.04 & 0.04 & 0.10 & 0.10 & 0.02 \\
\hline Max & 19.31 & 26.18 & 18.06 & 17.67 & 20.99 \\
\hline Mean & 4.60 & 5.11 & 4.71 & 4.28 & 4.80 \\
\hline SD & 2.90 & 3.41 & 3.08 & 2.69 & 3.70 \\
\hline Coefficient of Variation & 63.04 & 66.73 & 65.39 & 62.85 & 77.08 \\
\hline
\end{tabular}

Table 2: LS factor statistics with slope exponent constant

\begin{tabular}{|l|l|l|l|l|l|}
\hline Parameter & ASTER 30m & CARTO 10m & CARTO 30m & SRTM 30m & UAV 18cm \\
\hline Min & 0.04 & 0.04 & 0.09 & 0.09 & 0.03 \\
\hline Max & 957.53 & 776.71 & 678.59 & 556.65 & 64.21 \\
\hline Mean & 20.47 & 15.04 & 21.78 & 17.64 & 1.93 \\
\hline SD & 47.87 & 41.95 & 56.92 & 39.44 & 5.34 \\
\hline Coefficient of Variation & 233.85 & 278.92 & 261.34 & 223.58 & 276.68 \\
\hline
\end{tabular}

Table 3: LS factor statistics with spatially distributed slope exponent

\begin{tabular}{|l|l|l|l|l|l|}
\hline Parameter & ASTER 30m & CARTO 10m & CARTO 30m & SRTM 30m & UAV 18cm \\
\hline Min & 0.04 & 0.04 & 0.09 & 0.09 & 0.03 \\
\hline Max & 9.92 & 14.14 & 10.38 & 9.98 & 16.30 \\
\hline Mean & 3.59 & 4.62 & 3.73 & 3.34 & 7.22 \\
\hline SD & 2.19 & 2.90 & 2.36 & 2.07 & 5.23 \\
\hline Coefficient of Variation & 61.00 & 62.77 & 63.27 & 61.98 & 72.44 \\
\hline
\end{tabular}

Table 4: LS factor statistics with multiple flow algorithm 
Statistically comparing the values in terms of parameters like mean, standard deviation, and coefficient of variation, UAV DEM has similar values with ASTER, SRTM and CARTODEM in case of constant slope exponent as in Table 2. It is also observed that with increase in DEM resolution, higher LS factor values were observed in areas near streams. Comparing LS factor using different slope exponent values as given in Table 3, higher mean values obtained in spatially distributed slope exponent with the exception of UAV DEM. In case of comparison with single flow algorithm according to
(McCool et al., 1989) and multiple flow algorithm according to (Desmet \& Govers, 1996) shows that multiple flow algorithm has lower mean and standard deviation values than single flow algorithm with the exception of UAV DEM. With reference to Tables 3 and 4, it is also found that at higher resolution DEMs like CARTO DEM (10m) and UAV DEM $(18 \mathrm{~cm})$, there are lesser mean values when spatially distributed slope exponent is used and higher mean values in case of constant slope exponent and multiple flow direction algorithm.

\begin{tabular}{|c|c|c|c|c|c|c|}
\hline DEM & Slope class & Min & Max & Mean & SD & $\begin{array}{l}\text { Coefficient of } \\
\text { Variation }\end{array}$ \\
\hline \multirow[t]{4}{*}{ UAV $18 \mathrm{~cm}$} & $0-10$ & 0.02 & 1.38 & 0.56 & 0.48 & 85.71 \\
\hline & $10-25$ & 2.18 & 4.45 & 3.25 & 0.75 & 23.08 \\
\hline & $25-50$ & 5.08 & 13.19 & 7.76 & 2.4 & 30.93 \\
\hline & $>50$ & 7.73 & 12.87 & 9.74 & 1.73 & 17.76 \\
\hline \multirow[t]{4}{*}{ CARTO $10 \mathrm{~m}$} & & 1.45 & 11.05 & 5.2 & 2.67 & 51.35 \\
\hline & & 2.23 & 16.98 & 7.48 & 3.89 & 52 \\
\hline & & 1.45 & 10.84 & 6.69 & 2.78 & 41.55 \\
\hline & & 0.9 & 13.28 & 5.33 & 4.16 & 78.05 \\
\hline \multirow[t]{4}{*}{ CARTO 30m } & & 0.41 & 9.97 & 4.44 & 2.8 & 63.06 \\
\hline & & 0.79 & 9.31 & 5.77 & 2.18 & 37.78 \\
\hline & & 1.73 & 13.23 & 6.47 & 3.1 & 47.91 \\
\hline & & 0.44 & 14.61 & 4.71 & 5.05 & 107.22 \\
\hline \multirow[t]{4}{*}{ SRTM 30m } & & 0.85 & 11.17 & 4.47 & 3.33 & 74.5 \\
\hline & & 3.34 & 11.49 & 6.53 & 2.23 & 34.15 \\
\hline & & 0.83 & 9.31 & 5.02 & 2.63 & 52.39 \\
\hline & & 0.57 & 9.26 & 4.03 & 3.16 & 78.41 \\
\hline \multirow[t]{4}{*}{ ASTER $30 \mathrm{~m}$} & & 0.6 & 11.33 & 4.24 & 3.17 & 74.76 \\
\hline & & 1.42 & 13.72 & 6.41 & 3.22 & 50.23 \\
\hline & & 0.64 & 10.57 & 5.61 & 2.77 & 49.38 \\
\hline & & 0.1 & 8.77 & 4.04 & 2.94 & 72.77 \\
\hline
\end{tabular}

Table 5: LS factor statistics based on slope class of UAV DEM

\begin{tabular}{|c|c|c|c|c|c|c|}
\hline DEM & Slope class & Min & Max & Mean & SD & $\begin{array}{l}\text { Coefficient of } \\
\text { Variation }\end{array}$ \\
\hline \multirow[t]{4}{*}{ UAV $18 \mathrm{~cm}$} & $0-10$ & 0.02 & 1.38 & 0.56 & 0.48 & 85.71 \\
\hline & $10-25$ & 2.18 & 4.45 & 3.25 & 0.75 & 23.08 \\
\hline & $25-50$ & 5.08 & 13.19 & 7.76 & 2.4 & 30.93 \\
\hline & $>50$ & 7.73 & 12.87 & 9.74 & 1.73 & 17.76 \\
\hline \multirow[t]{4}{*}{ CARTO $10 \mathrm{~m}$} & $0-10$ & 0.37 & 1.2 & 0.56 & 0.27 & 48.21 \\
\hline & $10-25$ & 1.67 & 3.75 & 2.65 & 0.74 & 27.92 \\
\hline & $25-50$ & 4.34 & 7.24 & 5.44 & 0.99 & 18.2 \\
\hline & $>50$ & 7.5 & 14.25 & 9.85 & 1.97 & 20 \\
\hline \multirow[t]{4}{*}{ CARTO $30 \mathrm{~m}$} & $0-10$ & 0.24 & 1.1 & 0.73 & 0.26 & 35.62 \\
\hline & $10-25$ & 1.25 & 4.17 & 3.03 & 0.83 & 27.39 \\
\hline & $25-50$ & 3.9 & 10.99 & 6.47 & 1.89 & 29.21 \\
\hline & $>50$ & 7.32 & 11.73 & 9.53 & 1.54 & 16.16 \\
\hline \multirow[t]{4}{*}{ SRTM 30m } & $0-10$ & 0.3 & 1.7 & 0.87 & 0.44 & 50.57 \\
\hline & $10-25$ & 1.99 & 6.39 & 3.83 & 1.46 & 38.12 \\
\hline & $25-50$ & 4.54 & 8.75 & 6.75 & 1.23 & 18.22 \\
\hline & $>50$ & 7.75 & 11.02 & 9.27 & 1.14 & 12.3 \\
\hline \multirow[t]{4}{*}{ ASTER 30m } & $0-10$ & 0.44 & 1.4 & 0.79 & 0.29 & 36.71 \\
\hline & $10-25$ & 2.32 & 5.65 & 3.62 & 1 & 27.62 \\
\hline & $25-50$ & 4.54 & 10.96 & 6.66 & 1.91 & 28.68 \\
\hline & $>50$ & 8.71 & 12.32 & 9.99 & 1.17 & 11.71 \\
\hline
\end{tabular}

Table 6: LS factor statistics based on slope class of respective DEMs 
From the UAV DEM slope map, a number of random points are generated for each slope class with break values of 10,25 and 50 respectively. These points are used for extraction of LS factor values for each slope class. The Statistical parameters such as the mean, standard deviation are calculated from the extracted raster values. From Table 5, on comparing the values based on slope class of UAV DEM, it is found that the highest mean value occurred in the slope class of $>50$ from the UAV DEM. The highest standard deviation is found to occur at slope class $>50$ from CARTO $30 \mathrm{~m}$ DEM. At higher slope class in UAV DEM, higher mean values are obtained. It also shows that coarser DEMs like $10 \mathrm{~m}$ and $30 \mathrm{~m}$ fails to identify the micro-topographical variations that can be easily detected using UAV DEM.LS factor values showed comparable results for similar slope classes, across the different DEMs as shown in Table 6. For $0-10 \%$ slope category the mean LS factor values ranged from 0.56 in UAV DEM and CARTO DEM $10 \mathrm{~m}$ to 0.87 in SRTM DEM. Whereas in $>50 \%$ slope category the mean values comes in the range of 9.27 to 9.99 in SRTM DEM and ASTER DEM respectively.

\section{CONCLUSIONS:}

This study has done a comparison of LS factor for different scenarios obtaining significant results. Computation of LS factor and it's variation with DEM resolution is assessed by known methods. Also the effects of computational algorithms on LS factor are noted. Selection of the algorithm is important. The scope of this research can be extended on higher DEM resolutions with new algorithms. The LS factor thus computed helps in determining the level of soil loss through RUSLE model. The studies of similar nature are not found to be done before. More extensive studies need to be undertaken for field measurement of LS factor values, validation of results, and thus identifying the DEM resolution which can estimate LS factor most close to the reality.

\section{REFERENCES}

Desmet, P., \& Govers, G. (1996). A GIs procedure for automatically calculating the USLE LS factor on topographically complex landscape units. Journal of Soil and Water Conservation, 51(5), 427-433.

Hickey, R., Smith, A., \& Jankowski, P. (1994). Slope length calculations from a DEM within ARC/INFO GRID. Computers, Environment and Urban Systems, 18(5), 365-380.

Liu, H., Kiesel, J., Hörmann, G., \& Fohrer, N. (2011). Effects of DEM horizontal resolution and methods on calculating the slope length factor in gently rolling landscapes. Catena, 87(3), 368-375. https://doi.org/10.1016/j.catena.2011.07.003

McCool, D. K., Foster, G. R., Mutchler, C. K., \& Meyer, L. D. (1989). Revised slope length factor for the Universal Soil Loss Equation. Transactions of the ASAE, 32(5), 1571-1576.
Renard, K., Foster, G., Weesies, G., McCool, D., \& Yoder, D. (1997). Predicting soil erosion by water: a guide to conservation planning with the Revised Universal Soil Loss Equation (RUSLE). Agricultural Handbook No. 703. https://doi.org/DC0-16-048938-5 65-100.

Thompson, J. A., Bell, J. C., \& Butler, C. A. (2001). Digital elevation model resolution: Effects on terrain attribute calculation and quantitative soil-landscape modeling. Geoderma, 100(1-2), 67-89. https://doi.org/10.1016/S00167061(00)00081-1

Winchell, M. F., Jackson, S. H., Wadley, A. M., \& Srinivasan, R. (2008). Extension and validation of a geographic information system-based method for calculating the Revised Universal Soil Loss Equation length-slope factor for erosion risk assessments in large watersheds. Journal of Soil and Water Conservation, 63(3), 105-111.

Wischmeier, W. H., \& Smith, D. D. (1978). Predicting rainfall erosion losses-a guide to conservation planning. Predicting Rainfall Erosion Losses-a Guide to Conservation Planning. 